\title{
Níveis de Suplementação com Lactose na Dieta de Leitões Desmamados
}

\author{
Teresinha Marisa Bertol ${ }^{1}$, Jonas Irineu dos Santos Filho², Jorge Vítor Ludke ${ }^{3}$
}

RESUMO - Foram comparados quatro níveis de inclusão de lactose $(0,7,14$ e $21 \%)$ na dieta pré-inicial de leitões desmamados aos 21 dias de idade, com o objetivo de definir qual o melhor nível de lactose para a dieta de desmame nesta idade. As dietas experimentais foram fornecidas do dia do desmame até 14 dias após e os leitões foram acompanhados até o final da fase de creche, aos 35 dias após o desmame. O ganho de peso diário (GPD) e o consumo de ração diário (CRD) de 0 a 14 dias após o desmame aumentaram linearmente ( $\mathrm{P}<0,002, \mathrm{Y}=151+3,26 \mathrm{X}$ e $\mathrm{P}<0,0002, \mathrm{Y}=247+4,04 \mathrm{X}$, respectivamente), enquanto a conversão alimentar (CA) reduziu linearmente ( $\mathrm{P}<0,08, \mathrm{Y}=1,73-0,011 \mathrm{X})$, com o aumento dos níveis de lactose na dieta. No período total de creche (0 a 35 dias), o GPD e o ganho de peso total (GPT) aumentaram linearmente ( $\mathrm{P}<0,14, \mathrm{Y}=339+6 \mathrm{X}, \mathrm{Y}=11,86+0,23 \mathrm{X}$, respectivamente), com o aumento dos níveis de lactose. O peso médio dos leitões aos 14 (PM14), 28 (PM28) e 35 (PM35) dias após o desmame também elevou-se linearmente (P<0,006, $\mathrm{Y}=9,90+0,027 \mathrm{X}, \mathrm{P}<0,08, \mathrm{Y}=17,06+0,024 \mathrm{X}$ e $\mathrm{P}<0,14, \mathrm{Y}=19,81+0,223 \mathrm{X})$, em conseqüência do aumento dos níveis de lactose na dieta. Foi concluído que a suplementação da dieta com lactose nas duas primeiras semanas após o desmame melhorou o desempenho de leitões desmamados aos 21 dias de idade. A definição do melhor nível de inclusão de lactose nas dietas de desmame dependerá de uma avaliação do custo adicional desta suplementação em relação ao ganho obtido no desempenho.

Palavras-chave: fontes de carboidratos, desempenho, desmame, fase inicial, fase pré-inicial

\section{Dietary Lactose Levels for Weaning Pigs}

\begin{abstract}
The inclusion of four lactose levels (0, 7, 14 and 21\%) in pre-starter diets for piglets was studied to determine the best level of lactose inclusion in weanling diets at this age. The experimental diets were fed from the weaning day to 14 days post weaning, but the performance was followed until the end of the nursery phase, at 35 days post weaning. The average daily gain (ADG) and the daily intake (CRD) from 0 to 14 days linearly increased $(\mathrm{P}<0.002, \mathrm{Y}=151+3.26 \mathrm{X}$ and $\mathrm{P}<0.0002, \mathrm{Y}=247+4.04 \mathrm{X}$, respectively), while feed: gain ratio $(\mathrm{C} / \mathrm{A})$ showed linear reduction $(\mathrm{P}<0.08, \mathrm{Y}=1.73-0.011 \mathrm{X})$ as the dietary lactose levels increased. In the overall period of nursery ( 0 to 35 days), ADG and total weight gain (GPT) linearly improved ( $\mathrm{P}<0.14, \mathrm{Y}=339+6 \mathrm{X}, \mathrm{Y}=11.86+0.23 \mathrm{X}$, respectively), as the dietary lactose levels increased. The average live weight at 14 days (PM14), at 28 days (PM28) and at 35 days (PM35) post weaning also linearly improved $(\mathrm{P}<0.006, \mathrm{Y}=9.90+0.027 \mathrm{X}, \mathrm{P}<0.08, \mathrm{Y}=17.06+0.024 \mathrm{X}$ and $\mathrm{P}<0.14, \mathrm{Y}=19.81+0.223 \mathrm{X}$, respectively $)$ as the dietary lactose levels increased. It was concluded that feeding diets containing lactose on two first weeks post weaning improved the piglets performance weaned at 21 days of age. The best level of lactose inclusion in weanling diets at this age will depend on an evaluation of the additional cost of this supplementation related to the improvement at the performance.
\end{abstract}

Key Words: carbohydrates sources, performance, pre-starter phase, starter phase, weaning

\section{Introdução}

A lactose é uma fonte de energia importante para a sobrevivência dos leitões após o nascimento, em razão destes animais possuírem baixas reservas de gordura e baixa capacidade de reter calor. A maior parte da galactose absorvida é utilizada pelo fígado para repor o glicogênio hepático, enquanto a maior parte da glicose absorvida passa pelo fígado sem ser metabolizada, ficando disponível para corrigir a hipoglicemia e servir como fonte de energia para tecidos como o cérebro (BIRD e HARTMANN, 1994).
Possivelmente, a lactose desempenha o mesmo papel após o desmame, quando os leitões perdem parte de suas reservas de gordura, devido ao baixo consumo de alimento nos primeiros dias após o desmame e ao estresse, o qual acelera o metabolismo e aumenta a temperatura da zona de conforto neste período.

Nos primeiros dias após o nascimento, os leitões apresentam altos níveis de lactase, cuja atividade expressa por unidade de tecido intestinal reduz após as primeiras semanas (WALKER, 1959; MANNERS e STEVENS, 1972; EKSTROM et al., 1975; e JAMES et al., 1987). Entretanto, o índice de eficiência de

\footnotetext{
1 Zoot. M.Sc., EMBRAPA Suínos e Aves, Cx. Postal 21, 89700-000, Concórdia - SC. E-mail: tbertol@cnpsa.embrapa.br

2 Engㅇ․-Agro. M.Sc., EMBRAPA Suínos e Aves. E.mail: jonas@cnpsa.embrapa.br

3 Engo-.Agr. D.Sc., EMBRAPA Suínos e Aves. E.mail: jorge@cnpsa.embrapa.br
} 
digestão da lactose não se altera em leitões até os 18 dias de idade (BIRD et al., 1995), provavelmente em função da rápida taxa de crescimento do intestino delgado dos leitões nesta faixa de idade (WALKER, 1959; EKSTROM et al., 1975). BIRD et al. (1995) demonstraram que, embora o tempo necessário para hidrolizar a lactose no intestino dos leitões com 10 dias de idade parece limitar a taxa de absorção da galactose, a quantidade total de galactose absorvida 60 minutos após a ingestão de lactose intacta é comparável à absorção da galactose proveniente da lactose previamente hidrolizada, indicando, portanto, que não há limitação na hidrólise intestinal da lactose nesta idade que pudesse prejudicar a absorção dos seus componentes. O mesmo não ocorre em suínos adultos em fase de crescimento, na qual a hidrólise da lactose e a absorção da galactose são limitadas (RERAT et al., 1990), levando à produção de ácidos graxos voláteis no intestino grosso a partir da lactose não-digerida.

Os leitões aos 21 dias de idade apresentam o sistema digestivo em desenvolvimento e, à medida que o nível da lactase reduz gradativamente, ocorre aumento gradual no nível da maioria das outras enzimas digestivas, as quais atingem grau de atividade satisfatório, em média, aos 42 dias de idade (LINDEMAN et al., 1986). Isto faz com que a capacidade dos leitões para digerir amido, sacarose e óleos vegetais ainda seja limitada aos 21 dias de idade. VEGA et al. (1992) observaram que os leitões entre 2 e 20 dias de idade não conseguem adaptar o transporte dos monossacarídeos aos desafios qualitativos e quantitativos dos carboidratos da dieta, e a absorção dos monossacarídeos durante a fase de aleitamento é geneticamente programada. Portanto, para leitões desmamados com 21 dias de idade ou menos, é necessário incluir na dieta proporções adequadas das fontes de carboidratos que os leitões estão mais aptos a digerir, entre os quais a lactose se destaca.

O soro de leite em pó, a lactose cristalina e o soro de leite desproteinado são os três principais ingredientes utilizados como fonte de lactose em dietas para leitões. Estes subprodutos são amplamente utilizados nas dietas de desmame, porém, não há um indicador claro sobre quais níveis de lactose devem ser utilizados em cada idade de desmame. Este trabalho foi realizado com o objetivo de definir qual o melhor nível de lactose a ser utilizado em dietas de desmame, para leitões desmamados com 21 dias de idade.

\section{Material e Métodos}

Foram comparados quatro níveis de inclusão de lactose $(0,7,14$ e $21 \%)$ na dieta pré-inicial de leitões desmamados aos 21 dias de idade. As quatro dietas (Tabela 1) foram fornecidas do dia do desmame até 14 dias após, sendo que no período subseqüente foi fornecida uma única dieta (dieta inicial) com $7 \%$ de lactose a todos os leitões, durante 21 dias.

As dietas pré-iniciais foram formuladas substituindo-se amido de mandioca por lactose na mesma proporção, mantendo-se um nível fixo de caseinato de sódio (5\%). As rações foram formuladas com os valores de energia metabolizável(EM) obtidos com leitões para o caseinato de sódio e para a lactose, sendo 4613 e $3184 \mathrm{kcal} / \mathrm{kg}$, respectivamente (BERTOL e LUDKE, 1999). Os demais valores de energia metabolizável utilizados na formulação foram obtidos em tabelas de composição de alimentos. Para o amido de mandioca, o valor utilizado foi de $3367 \mathrm{kcal} / \mathrm{kg}$ (EMPRESA BRASILEIRA DE PESQUISA E AGROPECUÁRIA - EMBRAPA, 1991). À medida que se elevou o nível de lactose na dieta, o nível de óleo também aumentou (1,33 a 2,17\%), para manter as dietas isocalóricas. Outros nutrientes como $\mathrm{Ca}, \mathrm{P}$ disponível, proteína bruta (PB), lisina, metionina, metionina+cistina e treonina também foram mantidos constantes entre as dietas (Tabela 1).

Foram utilizados 96 leitões com idade média de $21,2 \pm 2,4$ dias, distribuídos em número de três do mesmo sexo por baia, totalizando quatro baias de macho e quatro de fêmea por tratamento. As unidades experimentais foram distribuídas nos tratamentos, seguindo um esquema em delineamento completamente casualizado.

Os leitões foram avaliados com relação ao desempenho, por meio do ganho de peso diário (GPD), do consumo de ração diário (CRD), da conversão alimentar (CA), dos pesos médios no início do experimento (PMI), aos 14 (PM14), 28 (PM28) e 35 (PM35) dias após o desmame e do ganho de peso total do início até o final da fase de creche (GPT=PM35PMI). Além da avaliação de desempenho, foi feita avaliação diária da incidência de diarréia nos primeiros 14 dias após o desmame, pelo seguinte escore: 0 fezes normais, 1 - fezes pastosas, 2 - fezes entre líquidas e pastosas e 3 - fezes líquidas.

Os dados de desempenho foram submetidos à análise de regressão (SAS, 1996). O número de leitões que apresentaram diarréia por pelo menos um dia, bem como o número de dias com diarréia, foi analisado pela Estatística de Qui-quadrado de Pearson (SAS, 1996). 
Tabela 1- Composição centesimal das rações experimentais Table 1 - Percentage composition of experimental diets

\begin{tabular}{|c|c|c|c|c|c|}
\hline \multirow[t]{2}{*}{$\begin{array}{l}\text { Ingredientes } \\
\text { Ingredient }\end{array}$} & \multicolumn{4}{|c|}{$\begin{array}{l}\text { Rações pré-iniciais (Pre-starter diets) } \\
\text { Níveis de lactose, \% (Lactose levels) }\end{array}$} & \multirow[t]{2}{*}{$\begin{array}{l}\text { Ração inicial } \\
\text { Starter diet }\end{array}$} \\
\hline & 0 & 7 & 14 & 21 & \\
\hline $\begin{array}{l}\text { Milho } \\
\text { Corn }\end{array}$ & 41,723 & 41,374 & 41,045 & 40,685 & 62,160 \\
\hline $\begin{array}{l}\text { Farelo soja } \\
\text { Soybean meal }\end{array}$ & 26,150 & 26,210 & 26,260 & 26,32 & 23,010 \\
\hline $\begin{array}{l}\text { Soro leite em pó } \\
\text { Dried whey }\end{array}$ & - & - & - & - & 10,000 \\
\hline $\begin{array}{l}\text { Caseinato de sódio } \\
\text { Sodium caseinate }\end{array}$ & 5,000 & 5,000 & 5,000 & 5,000 & - \\
\hline $\begin{array}{l}\text { Lactose } \\
\text { Lactose }\end{array}$ & 0,000 & 7,000 & 14,000 & 21,000 & - \\
\hline $\begin{array}{l}\text { Amido de mandioca } \\
\text { Cassava starch }\end{array}$ & 21,00 & 14,000 & 7,000 & - & - \\
\hline $\begin{array}{l}\text { Calcário } \\
\text { Limestone ground }\end{array}$ & 0,660 & 0,660 & 0,660 & 0,670 & 0,690 \\
\hline $\begin{array}{l}\text { Fosfato bicálcico } \\
\text { Dicalcium phosphate }\end{array}$ & 2,470 & 2,480 & 2,480 & 2,490 & 1,570 \\
\hline $\begin{array}{l}\text { Óleo bruto de soja } \\
\text { Soybean oil }\end{array}$ & 1,330 & 1,610 & 1,890 & 2,170 & 1,020 \\
\hline $\begin{array}{l}\mathrm{L} \text {-lisina } \mathrm{HCl} \\
\text { L-lysine } \mathrm{HCl}\end{array}$ & 0,157 & 0,155 & 0,154 & 0,153 & 0,230 \\
\hline $\begin{array}{l}\text { DL-metionina } \\
\text { DL-methionine }\end{array}$ & 0,110 & 0,111 & 0,111 & 0,112 & \\
\hline $\begin{array}{l}\text { Sal } \\
\text { Salt }\end{array}$ & 0,230 & 0,230 & 0,230 & 0,230 & 0,020 \\
\hline $\begin{array}{l}\text { Óxido de zinco } \\
\text { Zinc oxide }\end{array}$ & 0,370 & 0,370 & 0,370 & 0,370 & - \\
\hline $\begin{array}{l}\text { Cloreto de colina } 60 \% \\
\text { Choline chloride }\end{array}$ & 0,200 & 0,200 & 0,200 & 0,200 & 0,200 \\
\hline $\begin{array}{l}\text { Mist. vit. e mineral } \\
\text { Vitamin and mineral mix }\end{array}$ & 0,600 & 0,600 & 0,600 & 0,600 & 0,600 \\
\hline $\begin{array}{l}\text { Promotor de crescimento } \\
\text { Antibacterial agent }\end{array}$ & - & - & - & - & 0,500 \\
\hline $\begin{array}{l}\text { Proteína bruta }(\%) \\
\text { Crude protein }\end{array}$ & 20,00 & 20,00 & 20,00 & 20,00 & 17,22 \\
\hline $\begin{array}{l}\mathrm{EM}(\mathrm{kcal} / \mathrm{kg}) \\
M E\end{array}$ & 3360 & 3360 & 3360 & 3360 & 3300 \\
\hline $\begin{array}{l}\text { Cálcio }(\%) \\
\text { Calcium }\end{array}$ & 0,90 & 0,90 & 0,90 & 0,90 & 0,80 \\
\hline $\begin{array}{l}\text { Fósforo disponível (\%) } \\
\text { Available phosphorus }\end{array}$ & 0,55 & 0,56 & 0,56 & 0,56 & 0,43 \\
\hline $\begin{array}{l}\text { Lisina }(\%) \\
\text { Lysine }\end{array}$ & 1,40 & 1,40 & 1,40 & 1,40 & 1,15 \\
\hline $\begin{array}{l}\text { Metionina }(\%) \\
\text { Methionine }\end{array}$ & 0,51 & 0,51 & 0,51 & 0,51 & 0,29 \\
\hline $\begin{array}{l}\text { Metionina+cistina }(\%) \\
\text { Methionine +cistine }\end{array}$ & 0,80 & 0,80 & 0,80 & 0,80 & 0,62 \\
\hline $\begin{array}{l}\text { Treonina }(\%) \\
\text { Threonine }\end{array}$ & 0,84 & 0,84 & 0,84 & 0,84 & 0,75 \\
\hline
\end{tabular}


Foi desenvolvida também uma equação para avaliação econômica e tomada de decisão em relação ao uso dos diferentes níveis de lactose, considerando-se os dados de consumo total de ração durante toda a fase de creche, o ganho de peso total e o preço das rações e dos leitões.

\section{Resultados e Discussão}

Pode-se observar efeito bastante acentuado da suplementação com lactose sobre o GDP, o CRD e a CA, no período de 0 a 14 dias após o desmame (Tabela 2). Neste período, o aumento dos níveis de lactose na dieta acarretou acréscimo linear no GDP $(\mathrm{P}<0,002, \mathrm{Y}=151+3,26 \mathrm{X})$ e no $\mathrm{CRD}(\mathrm{P}<0,0002$, $\mathrm{Y}=247+4,04 \mathrm{X})$ e redução linear na $\mathrm{CA}(\mathrm{P}<0,08$, $\mathrm{Y}=1,73-0,011 \mathrm{X})$. O peso médio aos 14 dias (PM14) e o peso médio aos 28 dias após o desmame (PM28) também aumentaram linearmente $(\mathrm{P}<0,006, \mathrm{Y}=9,90$ $+0,027 \mathrm{X}$ e $\mathrm{P}<0,08, \mathrm{Y}=17,06+0,024 \mathrm{X}$, respectivamente), em conseqüência do aumento dos níveis de lactose na dieta (Tabela 3 ).

No período de 14 a 35 dias após o desmame, o GDP e o CRD não apresentaram efeito residual da suplementação prévia com lactose. Isto era esperado, pois nesta fase todos os leitões receberam a mesma dieta, com $7 \%$ de lactose. No período total de creche (0 a 35 dias), o GPD e o GPT aumentaram linearmente $(\mathrm{P}<0,14, \mathrm{Y}=339+6 \mathrm{X}, \mathrm{Y}=11,86+0,23 \mathrm{X}$, respectivamente), em função do aumento dos níveis de lactose na dieta nas duas primeiras semanas (Tabela 3 ). $\mathrm{O}$ mesmo ocorreu com o PM35 ( $\mathrm{P}<0,14, \mathrm{Y}=19,81+0,223 \mathrm{X})$.

$\mathrm{O}$ aumento no GDP obtido na primeira fase do experimento, com o acréscimo dos níveis de lactose da dieta, ocorreu principalmente em conseqüência de aumento no CRD, indicando que a lactose atua como uma espécie de palatabilizante, estimulando o consumo de ração. Houve incremento de 3,26 g no GPD e 4,04 g no CRD para cada unidade percentual de inclusão de lactose na dieta. A melhora observada na CA com o aumento dos níveis de lactose nos primeiros 14 dias do experimento foi de 0,011 unidades para cada unidade percentual de inclusão da lactose na dieta e também pode ter contribuído para a melhoria do ganho de peso nesta fase. Uma das possíveis explicações para a melhora da CA pode ser o fato de o intestino dos leitões jovens não conseguir adaptar o transporte dos monossacarídeos aos desafios qualitativos e quantitati-

Tabela 2 - Efeito dos níveis de lactose da dieta sobre o desempenho de leitões desmamados aos 21 dias de idade

Table 2 - Effect of dietary lactose levels on the performance of piglets weaned at 21 days of age

\begin{tabular}{|c|c|c|c|c|}
\hline & \multicolumn{4}{|c|}{ Níveis de lactose, \% - Lactose levels } \\
\hline & 0 & 7 & 14 & 21 \\
\hline & \multicolumn{4}{|c|}{0 a 14 dias - 0 to 14 days } \\
\hline $\begin{array}{l}\text { Ganho peso diário }{ }^{1}, \mathrm{~g} \\
\text { Daily gain, } g\end{array}$ & $142 \pm 73$ & $186 \pm 46$ & $191 \pm 44$ & $219 \pm 31$ \\
\hline $\begin{array}{l}\text { Consumo de ração diário }{ }^{1}, \mathrm{~g} \\
\text { Daily feed, } g\end{array}$ & $240 \pm 166$ & $280 \pm 30$ & $300 \pm 53$ & $334 \pm 47$ \\
\hline $\begin{array}{l}\text { Conversão alimentar }{ }^{2} \\
\text { Feed:gain ratio }\end{array}$ & $1,81 \pm 0,41$ & $1,55 \pm 0,25$ & $1,59 \pm 0,17$ & $1,53 \pm 0,14$ \\
\hline Ganho peso diário, $\mathrm{g}$ & $463 \pm 94$ & $\begin{array}{l}14 \text { a } 35 \text { dias } \\
488 \pm 63\end{array}$ & $\begin{array}{l}14 \text { to } 35 \text { day } \\
501 \pm 47\end{array}$ & $470 \pm 57$ \\
\hline $\begin{array}{l}\text { Daily gain, } g \\
\text { Consumo de ração diário, } g \\
\text { Daily feed, } g\end{array}$ & $845 \pm 158$ & $897 \pm 91$ & $878 \pm 97$ & $879 \pm 76$ \\
\hline $\begin{array}{l}\text { Conversão alimentar } \\
\text { Feed:gain ratio }\end{array}$ & $1,83 \pm 0,12$ & $1,85 \pm 0,12$ & $1,75 \pm 0,06$ & $1,88 \pm 0,10$ \\
\hline Ganho peso diário $^{3}, \mathrm{~g}$ & \multicolumn{4}{|c|}{0 a 35 dias - 0 to 35 days } \\
\hline $\begin{array}{l}\text { Daily gain, } g \\
\text { Consumo de ração diário, } \mathrm{g} \\
\text { Daily feed, } g\end{array}$ & $605 \pm 165$ & $651 \pm 58$ & $645 \pm 107$ & $661 \pm 61$ \\
\hline $\begin{array}{l}\text { Conversão alimentar } \\
\text { Feed:gain ratio }\end{array}$ & $1,80 \pm 0,10$ & $1,78 \pm 0,13$ & $1,71 \pm 0,05$ & $1,79 \pm 0,09$ \\
\hline $\begin{array}{l}\text { Ganho peso total }{ }^{3}, \mathrm{~kg} \\
\text { Total weight gain }\end{array}$ & $11,66 \pm 2,26$ & $12,86 \pm 1,59$ & $13,25 \pm 1,44$ & $12,94 \pm 1,51$ \\
\hline
\end{tabular}


Tabela 3 - Efeito dos níveis de lactose da dieta sobre o peso médio dos leitões em diferentes períodos

Table 3 - Effect of dietary lactose levels on the average live weight of piglets in different periods

\begin{tabular}{lcccc}
\hline $\begin{array}{l}\text { Período pós-desmame } \\
\text { Period postweaning }\end{array}$ & \multicolumn{4}{c}{$\begin{array}{c}\text { Níveis de lactose }(\%) \\
\text { Dietary lactose levels }\end{array}$} \\
\cline { 2 - 5 } & 0 & 7 & 14 & 21 \\
\hline $\begin{array}{l}\text { Dia do desmame }(\mathrm{kg}) \\
\text { Weaning day }\end{array}$ & $7,75 \pm 1,07$ & $7,59 \pm 1,50$ & $7,38 \pm 1,31$ & $7,62 \pm 1,14$ \\
14 dias $^{1}, \mathrm{~kg}-14$ day & $9,70 \pm 1,48$ & $10,20 \pm 1,24$ & $10,09 \pm 1,60$ & $10,69 \pm 1,23$ \\
28 dias $^{2}, \mathrm{~kg}-28$ day & $16,69 \pm 2,48$ & $17,48 \pm 1,90$ & $17,21 \pm 2,17$ & $17,80 \pm 1,73$ \\
35 dias $^{3}, \mathrm{~kg}-35$ day & $19,41 \pm 3,66$ & $20,45 \pm 3,37$ & $20,63 \pm 4,05$ & $20,56 \pm 3,13$ \\
\hline
\end{tabular}

${ }^{1}$ Efeito linear $(P<0,01),{ }^{2}$ Efeito linear $(P<0,08),{ }^{3}$ Efeito linear $(P<0,14)$.

${ }^{1}$ Linear response $(P<.01),{ }^{2}$ Linear response $(P<.08),{ }^{3}$ Linear response $(P<.14)$.

Tabela 4 - Efeito dos diferentes níveis de lactose da dieta sobre o número de leitões que apresentaram diarréia e número de leitões estratificados, de acordo com a duração da diarréia

Table 4 - Effect of dietary lactose levels on the number of piglets with diarrhea and on the number of piglets classified, regarding the length of the diarrhea

\begin{tabular}{|c|c|c|c|c|c|c|c|c|}
\hline \multirow[t]{2}{*}{$\begin{array}{l}\text { Níveis de lactose (\%) } \\
\text { Dietary lactose levels }\end{array}$} & \multirow{2}{*}{$\begin{array}{l}\text { Número total } \\
\text { leitões } \\
\text { Total number } \\
\text { of piglets }\end{array}$} & \multirow{2}{*}{$\begin{array}{l}\text { Número leitões } \\
\text { com diarréia }{ }^{1} \\
\text { Number of piglets } \\
\text { with diarrhea }\end{array}$} & \multicolumn{6}{|c|}{$\begin{array}{r}\text { Duração da diarréia }^{1} \text { (dias) } \\
\text { Length of diarrhea (days) }\end{array}$} \\
\hline & & & 1 & 2 & 3 & $\overline{4}$ & 5 & +5 \\
\hline 0 & 24 & 5 & 1 & 4 & 0 & 0 & 0 & 0 \\
\hline 7 & 24 & 7 & 7 & 0 & 0 & 0 & 0 & 0 \\
\hline 14 & 24 & 10 & 6 & 0 & 2 & 1 & 1 & 0 \\
\hline 21 & 24 & 4 & 3 & 0 & 0 & 0 & 1 & 0 \\
\hline
\end{tabular}

${ }_{1} P>0,05(P>.05)$.

vos da dieta e, portanto, poder processar apenas quantidades limitadas de produtos não-lácteos (VEGA et al., 1992). A superioridade da lactose sobre outras fontes de carboidratos para leitões desmamados precocemente (23 dias de idade) tem sido relatada também por outros pesquisadores, os quais relataram efeitos positivos sobre o desempenho (LEPINE et al., 1991; MAHAN, 1992; MAHAN, 1993; MAHAN e NEWTON, 1993; NESSMITH et al., 1997a) e a digestibilidade da energia e dos nutrientes da dieta (OWSLEY et al., 1986; TURLINGTON et al., 1989; BERTOL e LUDKE, 1999).

Após o desmame, ocorre aumento acentuado na atividade total das enzimas maltase e glicoamilase, induzido provavelmente pela presença do substrato e, também, por uma resposta adaptativa intrínseca, independente do consumo de alimento (KELLY et al., 1991). A atividade total da lactase tende a reduzir neste mesmo período, embora KELLY et al. (1991) não tenham obtido diferenças significativas entre os níveis desta enzima ao desmame (14 dias de idade) e sete dias após. Dessa forma, o trato intestinal do leitão adapta-se gradativamente a outras fontes de carboidratos, tornando possível a redução do nível de lactose na dieta em torno de 10 a 14 dias após o desmame.

Apesar da diferença absoluta entre os tratamentos, quanto ao peso médio dos leitões ter aumentado do $14^{\mathrm{O}}$ dia após o desmame até o 35ํo dia, onível de significância desta diferença reduziu no mesmo período. No período total, observou-se que os leitões que receberam as dietas com 7 e $14 \%$ de lactose ganharam 1,20 e $1,59 \mathrm{~kg}$ a mais de peso, respectivamente, até o final da fase de creche, do que aqueles que receberam a dieta sem lactose (Tabela 5).

$\mathrm{Na}$ fase de fornecimento das dietas pré-iniciais, não foi obtido um "plateau" em relação ao efeito da lactose sobre o desempenho, pois a resposta foi linear. Isto ocorreu provavelmente devido ao alto 
Tabela 5 - Consumo total de ração pré-inicial ( 0 a 14 dias) e inicial ( 14 a 35 dias) e diferença no ganho de peso total do desmame até o final da fase de creche entre a dieta sem lactose e as demais dietas

Table 5 - Total feed intake of pre-starter (0 to 14 days) and starter (14 to 35 days) diets and difference in the total weight gain from the weaning to the end of the nursery phase, among the diet without lactose and the other diets

\begin{tabular}{lcccc}
\hline & \multicolumn{4}{c}{$\begin{array}{c}\text { Níveis de lactose (\%) } \\
\text { Lactose level }\end{array}$} \\
\cline { 2 - 5 } & 0 & 7 & 14 & 21 \\
\hline CRT pré-inicial (kg) & 3,36 & 3,92 & 4,20 & 4,68 \\
CRT pre-starter & & & & \\
CRT inicial (kg) & 17,75 & 18,84 & 18,44 & 18,46 \\
$\begin{array}{l}\text { CRT starter } \\
\text { Diferença no ganho peso total (kg) } \\
\text { Difference in the total weight gain }\end{array}$ & & & & \\
\hline CRT consury & - & 1,20 & 1,59 & 1,28 \\
\hline
\end{tabular}

$\mathrm{CRT}=$ consumo de ração total (total feed intake).

nível de lactase intestinal nos leitões desta idade, o que possibilita a digestão e absorção de níveis elevados de lactose, e à capacidade limitada destes animais para digerir amido e outros carboidratos presentes em alimentos de origem vegetal. Considerando o período total de creche, embora ainda tenha ocorrido efeito linear, observa-se que o ganho de peso foi muito semelhante nos leitões que receberam qualquer um dos níveis de lactose na dieta pré-inicial. No entanto, a inclusão de uma fonte de proteína de alta digestibilidade, como o caseinato de sódio, em todas as dietas fornecidas de 0 a 14 dias após o desmame, pode ter reduzido o impacto benéfico da suplementação com lactose. TOUCHETTE et al. (1995) verificaram que, em dietas contendo plasma animal "spray-dried", os leitões necessitaram entre 0 e $15 \%$ de lactose para maximizar o desempenho, enquanto, em dietas sem plasma animal "spray-dried", os leitões necessitaram de 30 a $45 \%$ de lactose.

No entanto, a decisão sobre qual nível de lactose deve ser utilizado nas dietas de desmame deve também considerar o cálculo econômico. Com preços da lactose mais elevados, os níveis mais baixos serão mais econômicos e vice-versa, dependendo também do preço obtido pelos leitões. Dessa forma, o custo adicional da ração com lactose consumida durante toda a fase de creche não poderá ser superior ao valor recebido pelo peso produzido a mais em cada nível de inclusão de lactose. Utilizando-se os dados da Tabela 5, chegou-se às fórmulas abaixo, nas quais, utilizando-se também os preços das rações e o preço de venda dos leitões, pode-se determinar se é ou não lucrativa a inclusão da lactose e o nível mais vantajoso em determinado momento.

Para o nível de $7 \%$ de inclusão:

PL*1,2 > (3,92*PRPI7\%)-(3,36*PRPI0\%)+(1,09*PRI) em que

PL

$1,2=$ diferença entre o ganho de peso total médio dos leitões dos níveis 0 e $7 \%$

= consumo total médio de ração pré-inicial dos leitões do nível $7 \%$

PRPI7\%, PRPI0\% = preço/kg da ração pré-inicial com 7 e $0 \%$ de lactose, respectivamente. = consumo total médio de ração pré-inicial dos leitões do nível $0 \%$

= diferença entre o consumo total médio de ração inicial dos leitões dos níveis 0 e $7 \%$

PRI = preço $/ \mathrm{kg}$ da ração inicial

Para o nível de $14 \%$ de inclusão:

PL*1,59>(4,20*PRPI14\%)-(3,36*PRPI0\%)+(0,69*PRI)

Tanto o soro de leite em pó como a lactose cristalina ou o soro de leite desproteinado podem ser utilizados para suprir as necessidades de lactose na dieta dos leitões. NESSMITH et al. (1997b) verificaram que estas três fontes de lactose proporcionam resultados equivalentes no desempenho dos leitões, desde que sejam de boa qualidade e provenientes de processamento adequado. 


\section{Conclusões}

A suplementação da dieta com lactose nas duas primeiras semanas após o desmame melhorou o desempenho dos leitões desmamados aos 21 dias de idade.

A definição do melhor nível de inclusão de lactose nas dietas de desmame dependerá de uma avaliação do custo adicional desta suplementação em relação ao ganho obtido no desempenho.

\section{Referências Bibliográficas}

BERTOL, T.M., LUDKE, J.V. 1999. Determinação do balanço de energia e nitrogênio de alguns alimentos com leitões na fase inicial. R. Bras. Zootec., 28(6):1296-1304.

BIRD, P.H., ATWOOD, C.S.A., HARTMANN, P.E. 1995. The responses of blood galactose to oral doses of lactose, galactose plus glucose and milk to piglets. Br. J. Nut., 73(5):753-761.

BIRD, P.H., HARTMANN, P.E. 1994. The response in the blood of piglets to oral doses of galactose and glucose and intravenous administration of galactose. Br. J. Nut., 71(4):553-561.

EMPRESA BRASILEIRA DE PESQUISA E AGROPECUÁRIA - EMBRAPA. Centro Nacional de Pesquisa de Suínos e Aves. 1991. Tabela de composição química e valores energéticos de alimentos para suínos e aves. 3.ed. Concórdia. 97p. (EMBRAPA-CNPSA. Documentos, 19).

EKSTROM, K.E., BENEVENGA, N.J., GRUMMER, H. 1975. Changes in the intestinal lactase activity in the small intestine of two breeds of swine from birth to 6 weeks of age. J. Nut., 105:1032-1038.

JAMES, P.S., SMITH, M.W., TIVEY, D.R. et al. 1987. Epidermal growth factor selectively increases maltase and sucrase activities in neonatal piglet intestine. J. Physiology, 393:583-594.

KELLY, D., SMITH, J.A., McCRAKEN, K.J. 1991. Digestive development of the early-weaned pig. 1. Effect of continuous nutrient supply on the development of the digestive tract and on changes in digestive enzyme activity during the first week post-weaning. Br. J. Nut., 5(2):169-180.

LEPINE, A.J., MAHAN, D.C., CHUNG, Y.K. 1991. Growth performance of weanling pigs fed corn soybean meal diets with or without dried whey at various L-lysine $\mathrm{HCl}$ levels. J. Anim. Sci., 69(5):2026-2032.

LINDEMAN, M.D., CORNELIUS, S.G., EL KANDELGY, S.M. et al. 1986. Effect of age, weaning and diet on digestive enzyme levels in the piglet. J. Anim. Sci., 62(5):1298-1307.

MAHAN, D.C. 1992. Efficacy of dried whey and its lactalbumin and lactose components at two dietary lysine levels on postweaning pig performance and nitrogen balance. J. Anim. Sci., 70:2182-2187.
MAHAN, D.C. 1993. Evaluating two sources of dried whey and the effects of replacing the corn and dried whey component with corn gluten meal and lactose in the diets of weanling swine. J. Anim. Sci., 71(11):2860-2866.

MAHAN, D.C., NEWTON, E.A. 1993. Evaluation of feed grains with dried skim milk and added carbohydrate sources on weanling pig performance. J. Anim. Sci., 71(12):3376-3382.

MANNERS, M.J., STEVENS, J.A. 1972. Changes from birth to maturity in the pattern of distribution of lactase and sucrase activity in the mucosa of the small intestine of pigs. $B r . J$. Nut., 28:113-127.

NESSMITH JR., W.B., NELSSEN, J.L., TOKACH, M.D. et al. 1997a. Evaluation of the interrelationships among lactose and protein sources in diets for segregated early-weaned pigs. J. Anim. Sci., 75(12):3214-3221.

NESSMITH JR.., W.B., NELSSEN, J.L., TOKACH, M.D. et al. 1997b. Effects of substituting deproteinized whey and(or) crystalline lactose for dried whey on weanling pig performance. J. Anim. Sci., 75(12):3222-3228.

OWSLEY, W.F., ORR JR., D.E., TRIBBLE, L.F. 1986. Effects of nitrogen and energy source on nutrient digestibility in the young pig. J. Anim. Sci., 63:492-496.

RERAT, A., VAISSADE, P., VAUGELADE, P. 1990. Kinetics and balance of glucose and galactose appearance in the portal blood after intake of lactose of hydrolysed lactose in conscious pigs. Annals of Nutrition and Metabolism., 34:119-132.

SAS INSTITUTE INC. SAS System for Windows, release 6.12 Cary, NC, USA, 1996. 01 CD-ROM.

TOUCHETTE, K.J., CROW, S.D., ALLEE, G.L. et al. 1995. Lactose response is dependent on plasma in the diet of weaned pigs. J. Anim. Sci., 73:171. Supplement 1.

TURLINGTON, W.H., ALLEE, G.L., NELSSEN, J.L. 1989. Effects of protein and carbohydrate sources on digestibility and digesta flow rate in weaned pigs fed a high-fat, dry diet. J. Anim. Sci., 67(9):2333-2340.

VEGA, I.M., PUCHAL, A.A., BUDDINGTON, R.K. 1992. Intestinal amino acid and monosaccharide transport in suckling pigs fed milk replacers with different sources of carbohydrate. J. Nut., 122(12):2430-2439.

WALKER, D.M. 1959. The development of the digestive system of the young animal. II. Carbohydrase enzyme development in the young pig. J. Agric. Sci., 52:357-363.

Recebido em: 11/09/99

Aceito em: 30/03/00 